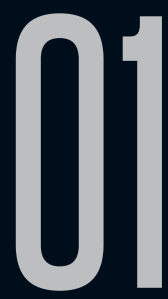

\title{
AS NUANCES DO GÓTICO: DO SETECENTOS À ATUALIDADE. JÚLIO FRANÇA E LUCIANA COLUCCI. 2017.
}

Maurício Cesar Menon (UTFPR)

Recebido em 07 out 2017. Maurício Cesar Menon possui mestrado e doutorado Aprovado em 17 out 2017. em Estudos Literários pela Universidade Estadual de Londrina (UEL) e pós-doutorado pela Universidade Federal do Paraná (UFPR). Atualmente é professor da UTFPR Campo Mourão PR, onde atua na graduação, como também nos programas de pós-graduação stricto sensu em Letras, da UTFPR Pato Branco PR, e Mestrado em Ensino de Ciências Humanas, Sociais e da Natureza, da UTFPR Londrina PR. Tem experiência na área de Literatura Brasileira, Portuguesa e Literatura Comparada, trabalhando principalmente nas seguintes áreas: Literatura Fantástica, Literatura e Sociedade, Ensino de Literatura. São seus temas de interesse e pesquisa a literatura gótica e seus desmembramentos, o fantástico, utopias e distopias e o romance histórico. É coordenador do Grupo de Pesquisa em Estudos da Narrativa (CNPq), na UTFPR de Campo Mourão PR. 


\section{DA ÁRVORE E DE SEUS RAMOS: UMA ABORDAGEM MULTIFACETADA SOBRE O GÓTICO}

As Nuances do Gótico (2017) é o título escolhido para o livro em cujo estofo encontram-se nove artigos, escritos por pesquisadores do Brasil e do exterior. Organizada por Júlio França, professor de Teoria da Literatura na Universidade do Estado do Rio de Janeiro - UERJ, e Luciana

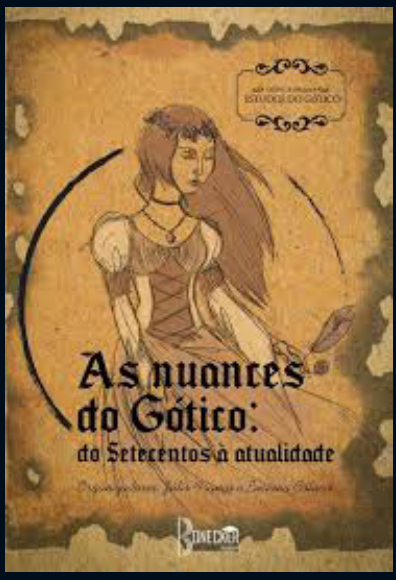
Colucci, professora de Literaturas de Expressão em Língua Inglesa na Universidade Federal do Triângulo Mineiro UFTM, a obra é fruto do I Seminário de Estudos do Gótico (SEG), realizado na UFTM, em 2014, onde se congregaram pesquisadores da área provenientes de diversos estados brasileiros. O evento que, recentemente, teve sua segunda edição, emergiu diretamente do Grupo de Pesquisa Estudos do Gótico, coordenado pelos professores que organizaram o presente volume.

Pesquisas sobre o gótico, suas nuances e desmembramentos, não se constituem fato tão recente, tendo em vista a vasta tradição acadêmica e crítica no que tange ao assunto, em se tratando de estudos desenvolvidos na Europa ou nos Estados Unidos. No Brasil, contudo, a pesquisa sobre os temas ligados ao fantástico, ao insólito, ao gótico e a todas as ramificações possíveis daí advindas, por muito tempo, mostrou-se ocasional, quase sempre produto de esforços isolados, possível consequência de uma tradição e crítica nos estudos sobre Literatura Brasileira pouco afeita ao reconhecimento dessa matéria. Tal cenário vem mudando nas últimas décadas, 
uma vez que, de forma crescente, criaram-se grupos de pesquisa que se dedicam a esses conteúdos. Vale ressaltar, nesse contexto, a importância do Grupo de Pesquisa Estudos do Gótico que tem protagonizado algumas ações importantes e dignas de nota: o livro aqui apresentado consiste em uma delas.

Logo no prefácio, redigido por Justin Edwards, professor catedrático em Gothic Studies na University of Stirling, destaca-se a importância desse grupo, pelo seu pioneirismo e pela contribuição das pesquisas engendradas sobre o objeto em múltiplos contextos aqui no Brasil. Na sequência, a apresentação é feita pelos professores Júlio França e Luciana Colucci, que destacam o caráter polissêmico do termo gótico, o que tem gerado variadas linhas teóricas e críticas de estudo. Na apresentação, entra-se em contato com a identidade do livro um dossiê que aborda, de acordo com o interesse de pesquisa de cada autor, algumas das inúmeras facetas possíveis dos estudos sobre o gótico e os seus ramos.

O primeiro artigo, assinado pelo professor Alexander Meireles da Silva, da Universidade Federal de Goiás - UFG, analisa uma novela de Howard Philips Lovecraft - a Sombra em Innsmouth (1936) - destacando como, pelo desenrolar da narrativa, é possível perceber a crítica feita pelo escritor sobre as profundas mudanças que ocorreram nos Estados Unidos na primeira metade do século XX. Meireles procura evidenciar como Lovecraft, nessa novela, trabalha com aspectos ligados à monstruosidade e ao hibridismo para alavancar discussões acerca da crescente presença de imigrantes em solo norte-americano. De maneira concisa e fiel ao recorte da análise, o professor consegue estabelecer elos entre Lovecraft e a ficção gótica finissecular inglesa, onde o tema do 
medo que se tem em relação ao outro também ganhou destaque, em obras como Drácula (1897), de Bram Stocker, e A Marca da Besta (1890), de Rudyard Kipling. No final, é revelada a atualidade da novela de Lovecraft, ao estabelecer uma conexão com os medos provenientes da imigração ilegal, dos terroristas e dos refugiados tanto nos Estados Unidos quanto na Europa, em pleno século XXI. Meireles arremata seu texto destacando que muito mais que uma crítica, a novela lovecraftiana "convida leitores contemporâneos à reflexão sobre o lugar do outro no contexto pós-moderno em que o sincretismo, a miscigenação e a hibridização trazem o enriquecimento de culturas nacionais" (p.20). Dessa forma, o artigo se configura como um texto em que o passado se une ao presente, extrapolando os limites temporais no que tange à discussão do tema, fato que comprova o poder que a literatura tem de romper limites, sejam eles de ordem espacial ou temporal, mostrando-se, por isso, significativa e portadora dos anseios humanos.

O segundo artigo, de Aparecido Donizete Rossi, professor de Literatura Inglesa da UNESP Araraquara SP, evoca desde o título "Pecados do pai: $O$ castelo de Otranto, um quarto de milênio depois" a gênese da literatura gótica. O estudo realizado por Rossi é amparado no convite metafórico feito por ele aos interlocutores de se abrir a "cripta do pai" não apenas para se observarem os restos mortais do ancestral, mas também para se visualizar a numerosa descendência deixada pelo progenitor, ou seja, as heranças literárias e artísticas possibilitadas por Walpole. Duplo, duplicação, dois, dupla, duplicidade, reduplicação são os termos que regem e organizam o eixo da impecável análise, feita pelo professor, daquele que é considerado o primeiro romance gótico da história literária. 
Partindo dos dois prefácios presentes em O Castelo de Otranto, e amparado pelo conceito de criptomímesis, são levantadas desde questões relativas à ordem estético-estrutural da obra ligadas ao clássico tema gótico, estabelecido nessa narrativa, do pecado do(s) pai(s) que recai (em) sobre os filhos, até questões históricas ligadas à época de Walpole. Rossi, sistematicamente atrelado à metáfora por ele criada para sua investigação, sonda os "restos mortais" presentes na cripta do escritor inglês e pontua dali o nascimento de um gênero que se estenderá e será reduplicado em ramos diversos ao longo dos séculos subsequentes - análogo à ideia da maldição paterna que atinge as gerações vindouras:

“(...) é o que hoje entendemos não apenas como romance gótico, mas sim como gênero gótico, que tem vida e história próprias, distintas da vida e da história do romance. Isso porque o gótico não se restringe aos suportes escritos da ficção, mas se manifesta, também, com a mesma potencialidade, em suportes tão diversos quanto o cinema, a narrativa gráfica (graphic novel), a moda, a Internet e o videogame" (2014, p.33).

Ao lado dessa linha mestra de abordagem, o texto é sustentado por sólidas bases teóricas, tangenciando também uma série de outros textos ficcionais ao se estabelecerem determinadas relações temáticas ou estéticas. Ao final, fica claro ao leitor que a própria intencionalidade do artigo também se duplica: se por um lado ele se compõe como um painel que permite visualizar o gótico e seus desmembramentos, por outro ele se constitui como uma digna homenagem (o texto é de 2014) aos duzentos e cinquenta anos da publicação de $O$ Castelo de Otranto. 
$\mathrm{Na}$ sequência do trabalho desenvolvido pelo docente da UNESP de Araraquara, desponta o artigo escrito por Cláudio Zanini, professor de Língua Inglesa e Literatura na Universidade Federal de Ciências da Saúde de Porto Alegre - UFCSPA. De forma clara fixase o objetivo central do texto: aproximar, comparativamente, duas obras literárias que não se encontram atreladas à tradição de análise sob a perspectiva teórica do gótico - Os 120 Dias de Sodoma (1785), do Marquês de Sade, e Assombro (2005), de Chuck Palahniuk. Ao se compararem tais romances, é permitido ao leitor entrar em contato com Sade escritor, uma vez que, grosso modo, ele é muito mais conhecido pelo adjetivo derivado de si que pelas próprias obras escritas, como também vislumbrar outra obra de Palahniuk que não seja o instigante Clube da Luta (1996) que o consagrou, o que se deve em parte à versão fílmica (1999), dirigida por David Fincher. Zanini desenvolve uma coesa linha de análise, mostrando similaridades entre as obras no que confere à enunciação narrativa das histórias que integram cada romance. Em ambos os casos trata-se de um encontro entre pessoas que possuem algo em comum e que se reúnem em um lugar atípico para desfiarem suas histórias: de um lado encontram-se os sádicos libertinos isolados num castelo e, de outro, os escritores confinados em retiro em um teatro abandonado.

O artigo procura demonstrar de que maneira é possível unir os temas provenientes das histórias dos diversos narradores, cujas temáticas perpassam pelos caminhos do escatológico, do grotesco, do bizarro e do violento, à ideia de transgressão, presente no gótico desde suas origens. Ganham destaque na análise não apenas os temas ligados à perversão, mas também os recursos estilísticos 
empregados pelos escritores, como a escolha de epítetos para designar os contadores das histórias contidas nos romances. Ao final, procura-se mostrar de que forma Palahniuk tornou-se aprendiz de Sade, numa espécie de "pedagogia da desumanização", no que diz respeito aos ecos que reverberam da obra do autor francês sobre o autor norte-americano. De alguma maneira, conclui o ensaísta, os leitores atuais também, seja num movimento de aproximação ou de afastamento, seja por gosto ou por repulsa, obtêm certa espécie de conhecimento dessa didatologia.

O capítulo seguinte, concebido por Fernando Monteiro de Barros, professor de Literatura Brasileira na Faculdade de Formação de Professores da Universidade do Estado do Rio de Janeiro FFP/UERJ, destaca-se por sua singularidade ao trazer a poesia decadentista de Teotônio Freire para o domínio da análise sob a perspectiva do gótico. Paulatinamente e com aguçada propriedade o professor encaminha a abordagem, partindo de pressupostos teóricos sobre o decadentismo tanto europeu quanto brasileiro e chegando aos poemas do escritor pernambucano. A abordagem dada ao tema do trabalho é análoga à imagem de uma sombra que, originária no gótico do século XVIII, avança sutilmente pelas décadas seguintes, desconhecendo limites geográficos, imprimindo sua marca na produção literária de final de século XIX e início do século XX. Fernando de Barros não só apresenta os poemas de um escritor que merece maior luz nos estudos sobre Literatura Brasileira, como também destaca os principais pontos a serem observados nesses poemas no que se refere às marcas ou às imagens do gótico, especialmente aquelas ligadas ao sublime, ao medievo, ao passado que assombra o presente. Dentre todos os poemas analisados pelo 
professor reproduz-se, aqui, a título de ilustração, alguns versos de Contraste, por sintetizarem as principais marcas ou imagens do gótico/decadentismo elencadas pelo estudioso: "Essa abadia imensa levantada/Do monte à grimpa, - austera sentinela/Que vara o céu com a torre em ponta ousada (...)/Sob o solo, porém se abrem geenas/De ais e soluços, ferros e correntes(...)/Há maldições e prantos inclementes (...)" (p.86-87). O artigo do professor contribui para maior discernimento sobre um assunto que, durante muito tempo, ficou à margem dos estudos e dos estudiosos de Literatura Brasileira e, por isso, integra um campo do qual muito se tem ainda a colher.

Sobre a esfera dessa seara é que se debruça Flavio García, professor da Universidade do Estado do Rio de Janeiro - UERJ e fundador do GT da ANPOLL "Vertentes do Insólito Ficcional". O texto denominado "Transparências entre a novela gótica e a narrativa fantástica: trânsitos ininterruptos (que se podem ver na obra de Mutilo Rubião)" versa, num primeiro momento, a respeito da forma que o gótico estabelece-se como o fundamento da literatura fantástica, amparado nos estudos desenvolvidos por Maria Leonor Machado de Souza, Filipe Furtado e David Roas. Após apresentação dos fundamentos teóricos, García introduz ao leitor o objeto de sua análise: o conto "As Unhas", de Murilo Rubião. Tratase de um texto inédito do autor mineiro que não consta nas edições de suas obras, vindo a público apenas em novembro de 1994 e sobre o qual o estudioso já escrevera um ensaio. Conhecedor da obra de Rubião, Flavio García analisa o texto com o cuidado de não cair em conclusões precipitadas, tendo em vista o escritor mineiro ser um dos mais emblemáticos da Literatura Brasileira 
do século XX. O professor levanta os aspectos ligados ao insólito ficcional amarrando-os a certas marcas presentes no gótico ou a outras reabilitadas pela Literatura Fantástica dos séculos XIX e XX. Desse trânsito entre elementos e épocas sucessivas surge a base de composição do artigo que, além de contribuir para os estudos sobre Murilo Rubião (autor que exclusivamente lidou com o insólito em sua ficção), indiretamente também comprova como a Literatura Brasileira, definitivamente, acolheu em seus domínios temas para os quais pouco se deu visibilidade ao longo da tradição crítica desenvolvida em território nacional.

Trazendo esclarecimento sobre essa questão da tradição crítica é que surge o próximo artigo "O Sequestro do Gótico no Brasil", de Júlio França (UERJ). Para aqueles que conhecem a célebre crítica desenvolvida por Haroldo de Campos sobre o (não) lugar do Barroco na Formação da Literatura Brasileira, de Antonio Candido, imediatamente já se delineia a abordagem que será feita. $\mathrm{O}$ professor, reconhecido como uma das autoridades sobre o assunto no Brasil, procura de maneira didática levantar algumas hipóteses para o fato de a História e a Crítica Literárias brasileiras terem se esquivado ou simplesmente ignorado as temáticas relativas ao gótico e aos seus ramos, ou às transformações que o gênero sofreu no Brasil. A partir dessas hipóteses, França também fornece algumas conclusões como

"Fazendo convergir a observação de Hansen com o modelo de Abrams, poderíamos afirmar que a crítica brasileira tende a abordagens miméticas e expressivas. Em consequência dessa ênfase nos atributos políticos e biográficos das obras literárias, as narrativas góticas foram compreendidas ou como 
algo estrangeiro e alheio à realidade brasileira, ou como sintomas de distúrbios e idiossincrasias psicológicas de seus autores" (p.115).

Partindo dessas conclusões, o autor do artigo registra uma espécie de comparação entre elementos convencionais da literatura gótica e algumas linhas investigativas possíveis sobre a presença da tradição gótica na literatura brasileira. Os elementos góticos pontuados são o locus horribilis, a presença fantasmagórica do passado e a personagem monstruosa; as linhas investigativas constituem-se de o Gótico e as origens do romance no Brasil, o Gótico e a temática da escravidão, o Gótico e o Naturalismo, o Gótico e a Literatura Decadente, o Gótico e a Literatura de Crime, o Gótico e os Romances de Sensação e o Gótico e os Regionalismos. Fica evidente, por fim, que ao aproximar os elementos das linhas temáticas o autor não pretendeu desenvolver um estudo sobre as influências do gótico europeu no Brasil, mas sim a partir do Gótico como uma concepção ficcional que expressa os medos e anseios humanos, por isso presente na literatura nacional.

O capítulo seguinte, composto pelo artigo "Legal Fictions: Gothic and the Spectre of the Law in Charles Brockden Brown's Edgar Huntly; or Memoirs of a Sleep-Walker", assinado por Justin D. Edwards (University of Stirling), une reflexões acerca do Direito e da Lei às discussões sobre o período colonial na América do Norte, ambas extraídas da leitura cuidadosa do romance de Brockden Brown mencionado no título. Embasado em concepções teóricas de grande envergadura como as de Homi Bhabha, Jacques Derrida, David Punter, entre outros, o professor norte-americano desenvolve uma análise de assuntos pertinentes à forma como a 
história e a lei do Estados Unidos foram se constituindo, sem perder de vista os elementos góticos contratados pelo romancista a fim de destacar esses assuntos. Um dos pontos reiterados ao longo do texto de Edwards é o fato de como a lei pode ser dual, sujeita a vários componentes como a interpretação, o contexto histórico, o poder estabelecido, e a cultura dominante. A lei surge, dessa forma, como um grande espectro do passado que assombra o presente e o porvir, revelando paradoxalmente seu poder e sua fragilidade. Importa notar que no decorrer da análise, o autor não perde de vista o texto ficcional que se propõe a trabalhar; este é o ponto de partida de onde se alavancam as observações e também o de chegada, de onde se extraem as conclusões. Edwards prova, assim, como um grande escritor é capaz, tal qual num jogo de xadrez, de movimentar personagens dentro de uma trama bem imbricada, denunciando aspectos de ordem sócio-política que extrapolam a ficção e, por isso, se fazem sempre atuais.

Luciana Colucci, da UFTM, dá seguimento à variedade de artigos apresentados no livro aqui resenhado, concebendo um texto no qual o espaço e o mobiliário são esquadrinhados sob o foco da topoanálise na literatura gótica. As teorias sobre espaço desenvolvidas por Bachelard e Ozíris Borges Filho fornecem, entre outras, o viés teórico para o estudo, mas é em Edgar Allan Poe, mais precisamente em The Philosophy of Furniture (1840), que a professora concentra seu foco de atenção, trabalhando a partir daí a ideia de uma topoanálise do gótico. Colucci maneja com precisão diversos materiais teóricos e ficcionais a fim de comprovar a concepção que desenvolve e não se furta de abordar analiticamente as minudências que muitas vezes, aos olhos do leitor comum, 
passam despercebidas. Um dos pontos altos do artigo é aquele em que a intelectual demonstra como em Poe a composição do espaço, do mobiliário e dos ornamentos encontram-se conjugados para se comunicarem com os sentidos humanos, aguçando-os a ponto de produzir determinado efeito. O que a pesquisadora revela, em vista disso, excede em muito o inventário de elementos presentes na obra do escritor norte-americano, ela consegue, à maneira de Erich Auerbach, adentrar as filigranas do texto e, dali, extrair um sentido maior, revelando uma espécie de arquitetura na qual os elementos estéticos e estruturais trabalham favorecendo o conteúdo, assegurando-lhe a força comunicativa com a qual se impõe diante do leitor de forma atemporal.

O último artigo do livro, escrito por Marisa Martins Gama-Khalil, professora da Universidade Federal de Uberlândia - UFU, discorre sobre a maneira como a escritora Lygia Fagundes Telles revisita o gótico em alguns de seus textos. Os contos "A mão no ombro", "O noivo", "A chave na porta" e "O encontro" constituem os objetos de análise e são explorados a partir das imagens dos espaços e da morte neles contidas. Para tanto, a ensaísta fornece ao leitor, antes de se iniciarem as análises propriamente ditas, uma esclarecedora perspectiva de que maneira a morte é redimensionada na narrativa gótica e de como a ambientação, geralmente apresentada em um contexto noturno, irmana-se a essa temática. A análise desses contos feita pela professora, sem cair na facilidade das generalizações, fornece uma espécie de clave de leitura para as obras de Telles que atendem à demanda dos temas insólitos, ao identificar alguns traços comuns e recorrentes na obra da escritora paulista; isso só se torna possível a partir de uma leitura cuidadosa que demonstra 
reconhecimento do território pelo qual se embrenha. Importa notar a relevância de se abordar a obra de Lygia Fagundes Telles no contexto do livro aqui resenhado, tendo em vista a escritora integrar indiscutivelmente o panteão de escritores brasileiros que transitam ou transitaram de modo efetivo pelos liames do fantástico.

Ao se examinar o conjunto de textos que compõem As nuances do gótico: do Setecentos à atualidade fica notório como o livro sinaliza para uma multiplicidade, fruto de um esforço conjunto que agrega pesquisadores de diversas localidades e promove abordagens de matizes variados. O gótico é apresentado, dessa forma, tal como uma grande árvore de profundas raízes e de cujos galhos surgem tantos ramos quanto permite a inventividade humana. O livro integra um amplo esforço de cooperação sem a qual, provavelmente, não teria vindo à luz - prova de que, num país como o Brasil, onde a pesquisa é muitas vezes maltratada, o unir das forças em torno de um ideal comum seja, talvez, uma das alternativas mais viáveis para a manutenção dos estudos em torno da literatura, desvendando-Ihe o caráter permanente de diálogo com as questões humanas que a todos dizem respeito. 